\title{
A imagem na pesquisa qualitativa em saúde
}

\author{
The image in qualitative research in health
}

Marta Pimenta Velloso ${ }^{1}$

Maria Beatriz Lisbôa Guimarães ${ }^{1}$

${ }^{1}$ Departamento de

Abstract This paper explores the use of the image as a methodological instrument in qualitative research in health. It is divided into two parts. The first part, which is theoretical in perspective, deals with aspects of anthropological fieldwork in which different views interact in the interpretation, either in the speech of the social actor or in the image that is produced. The second part describes two empirical studies on the image as a methodological instrument to obtain qualitative data, presenting research with images recorded on DVD and photographs of garbage pickers and garbage collectors, respectively. The conclusion reached is that the image can be used both as a complementary example, and as an instrument in qualitative research. Participant observation and interviews can be supplemented with the image but the image itself generates an accumulation of information, stimulating the viewer's ability to comprehend.

Key words Image, Subjectivity, Qualitative research, Garbage pickers, Garbage collectors
Resumo O presente artigo consiste em explorar o uso da imagem como instrumento metodológico na pesquisa qualitativa em saúde, sendo dividido em duas partes. A primeira, de cunho teórico, aborda aspectos do trabalho de campo antropológico em que diferentes olhares interagem na interpretação, seja na fala do ator social, seja na imagem produzida. Já a segunda, descreve dois estudos empíricos sobre a imagem como recurso metodológico na obtenção de dados qualitativos, apresentando pesquisas com imagens registradas em DVD e em fotografias, respectivamente, de coletores e catadoras de lixo. Conclui-se que a imagem pode ser utilizada tanto como complemento ilustrativo, quanto como instrumento na pesquisa qualitativa. A observação participante e as entrevistas podem ser complementadas com a imagem, mas a imagem gera por si só um acúmulo de informações, estimulando a capacidade de apreensão do espectador.

Palavras-chave Imagem, Subjetividade, Pesquisa qualitativa, Catadores de lixo, Coletores de lixo 


\section{Introdução}

O artigo aborda a imagem como ferramenta metodológica em termos teóricos e, em relação a duas categorias de trabalhadores. A primeira abordagem apresenta a análise resultante da interação de imagens relacionadas ao processo de trabalho dos coletores de lixo da Companhia Municipal de Limpeza Urbana do Rio de Janeiro (Comlurb) e de entrevistas realizadas com esses trabalhadores.

Já a segunda focaliza o trabalho de catadoras de lixo, que trabalham de forma autônoma catando material reciclável para comercializá-lo. Nesse caso, o recurso da imagem foi utilizado em sobreposição às falas - descrevendo imagens fotográficas vinculadas ao trabalho das catadoras, de objetos recolhidos no lixo e de suas moradias. Percebemos a satisfação das catadoras na descoberta de objetos encontrados no lixo, por meio de fotografias ou de suas falas - percepções imagéticas e faladas - sendo que a imagem, nesse caso, traduz de forma mais intensa o valor atribuído pela catadora ao objeto adquirido.

No Brasil, a desigualdade social e a diversidade cultural da população propiciam o conhecimento veiculado pela imagem. Esta, pode ser mais acessível do que a palavra falada, pois pode estimular a capacidade de apreensão do espectador. A fala pode ser complementada com a imagem, mas a imagem gera por si só um acúmulo de informações. Essas informações, veiculadas pela imagem, vão variar em conteúdo e forma segundo o fotógrafo, o fotografado e o observador.

No entanto, cabe ressaltar os critérios cuidadosos que devemos adotar ao trabalharmos com a imagem na pesquisa qualitativa em saúde, ou seja, referimo-nos à ética em utilizar essas imagens com consentimento do ator social, seguindo as normas do Conselho de Ética em Pesquisa (CEP) e, também, o contexto histórico na exploração da imagem a ser analisada.

O objetivo do presente artigo consiste em explorar o uso da imagem como instrumento metodológico na pesquisa qualitativa em saúde, sendo dividido em duas partes, a primeira de cunho mais teórico: o pesquisador e a pureza do objeto, e a segunda referente à descrição de duas pesquisas empíricas: imagens do trabalho de coletores e catadoras de lixo.

\section{O pesquisador e a pureza do objeto}

A sociologia e a antropologia têm sido criteriosas em separar o que é estranho à suposta pureza do objeto, sobretudo a inserção da subjetividade do pesquisador na formulação e na investigação de seu tema de estudo. No entanto, pouco tem sido feito em relação à imagem e ao seu registro, numa sociedade que vem se tornando cada vez mais visual, com a imagem em processo acelerado de exploração.

O pesquisador, ao entrar na realidade investigada, interage e, ao interagir com ela, altera necessariamente o conhecimento do senso comum referencial das populações estudadas; do mesmo modo que, comumente, o fotografado, especialmente se fotografado por um estranho, arrumase, faz pose ou até se veste "apropriadamente" para posar. Martins ${ }^{1}$ chama a atenção para o vestuário usado como disfarce e a maquiagem como instrumento de ficção da identidade e da autoimagem, verificando que podem fazer mais revelações sociológicas do que a fotografia invasora do sociólogo, a qual flagra desprevenidos seus sujeitos de referência. O paparazzo invasor ou aquele que pratica o voyerismo fotográfico pode considerar um triunfo fotografar alguém que tenta se proteger contra esse tipo de violência visual. Mas, de fato, terá fotografado na pessoa do outro o que é, imaginariamente, sua própria pessoa, o seu ego num corpo alheio. Numa análise sociológica, essa fotografia é documento sobre a mentalidade do fotógrafo, e não, fundamentalmente, documento da pessoa fotografada.

Assim, o sociólogo deve obter a informação visual que procura em função dos pressupostos teóricos de sua pesquisa, mas obterá um dado mutilado e desprovido da informação cultural que o situa e explica se não observar as regras de acesso a situações e espaços sociais. Sobretudo se desconhecer a cultura visual e o olhar das populações que visita e estuda. O pesquisador pode encontrar o material de referência para uma sociologia da fotografia e da imagem no que se interpreta, e não simples e mecanicamente no que se vê.

$\mathrm{Na}$ pesquisa em ciências sociais costumamos tomar como instrumento metodológico a fala dos atores sociais, mas a imagem fotográfica, por ser flagrante, pode ser uma ferramenta indispensável na leitura dos acontecimentos e dos fenômenos da sociedade. Tomar a fotografia como documento social, em termos absolutos, envolve as mesmas dificuldades que há quando se tomam a palavra falada, o depoimento e a entrevista, em termos absolutos, como referência so- 
ciológica, que são as dificuldades de sua insuficiência e de suas limitações.

As análises de várias correntes da sociologia e da antropologia têm como material não a realidade strictu sensu, mas a interpretação da realidade pelo homem simples, a interpretação que torna sua vida possível e inteligível. Segundo Martins ${ }^{1}$, quando as pessoas dão entrevistas a um pesquisador relatam fatos, interpretando-os. O que os cientistas analisam e interpretam é a interpretação que esse homem comum faz dos processos interativos que vivencia, no confronto com as referências estruturais e mesmo históricas que revelam e iluminam o que é próprio e objetivamente social e que, no mais das vezes, não estão ao alcance de sua compreensão.

Segundo Geertz ${ }^{2}$, os textos antropológicos são interpretações de segunda e terceira mão, na medida em que somente o ator social faz a interpretação em primeira mão: é a sua cultura. Nesse sentido, a antropologia se aproxima da literatura, pois os textos antropológicos abordam ficções de ficções, não que sejam falsos, mas no sentido de ser algo construído. O que os etnógrafos escrevem é o significado ou a interpretação do acontecimento de falar, não o acontecimento como acontecimento. Ao escrever o discurso social, os pesquisadores o transformam de acontecimento passado, que existe apenas em seu próprio momento de ocorrência, em um relato que pode ser consultado posteriormente.

O fundamental para a antropologia é compreender as manifestações de cada cultura em seus próprios termos, a partir "de dentro", mas sem se confundir com a visão dos atores sociais. Geertz ${ }^{2}$ assume a cultura como formada por teias de significados em que os homens encontramse emaranhados, e o trabalho do antropólogo consiste em procurar por significados em meio a essas teias, ou seja, tentar ler, no sentido de construir uma leitura de um manuscrito estranho, cheio de incoerências. Qualquer generalidade que o pesquisador possa perceber emergirá da delicadeza de certas distinções e não da amplidão das abstrações. O objetivo do trabalho científico consiste em tirar conclusões a partir de fatos pequenos, mas densamente entrelaçados.

O reconhecimento da fotografia como documento social veio acompanhado da consciência de que a fotografia tem as limitações da visão socialmente situada do fotógrafo e da invisibilidade de várias dimensões da realidade social. Assim como os sociólogos reconhecem ocultações que pediam o desenvolvimento de técnicas de pesquisa que permitissem nelas penetrar, os fotógrafos sociais têm desenvolvido técnicas para obter imagens daquilo que é invisível ao olhar dominante. Um recurso que vem sendo utilizado é o de entregar máquinas fotográficas aos atores sociais envolvidos na pesquisa.

$\mathrm{Na}$ obra do fotógrafo cego Evegen Bavcar, que é fotógrafo com estilo próprio, temos evidência propriamente sociológica de como a fotografia se torna um instrumento da modernidade e, portanto, da complexidade de sua realização e da sua leitura. Bavcar fotografa, mas não pode ver o que está fotografando nem a fotografia que resultou do ato do que foi fotografado. Ele vê através dos indícios não visuais, por meio da audição, do olfato e do tato, coisa que os que vêem também fazem, mas não sabem porque estão subjugados por uma espécie de ditadura do olhar, ditadura que é intensa nos urbanos e menos intensa nos rurais e mais intensa na classe média do que nas classes populares. Por outro lado, a fotografia de Bavcar é apenas para os outros verem, já que ele próprio não pode vê-la. No entanto, ele vê através do que os outros dizem que estão vendo em suas fotos. Mas, não assume, necessariamente, a subjetividade do ver alheio. Escolhe, nas impressões que lhes são passadas, aquilo que corresponde à imagem que construiu na sua imaginação, filtrada, agora, pelo conjunto desencontrado dessas impressões. A importância sociológica da singular condição de fotógrafo de Bavcar está no fato de que a fotografia se propõe a ser aquilo que efetivamente é: documento de um jogo de imaginações e não de figuras e contornos, documento de processos interativos e não de um olhar solitário ${ }^{1}$.

Registros de imagens interativas, resultantes de diferentes olhares, foram vistas na exposição intitulada "Os Sonhos de Grete Stern", produzida pela montagem de fotografias femininas elaboradas pela fotógrafa Grete Stern ${ }^{3}$. Grete nasceu em Wuppertal (1904) e morreu em Buenos Aires (1999), sendo responsável pelo primeiro curso de fotografia na Bauhaus (Dessau, 1929). O museu Lasar Segall escolheu 46 de suas fotomontagens publicadas em Idílio - La Revista Juvenil e Femenina, de 1948 a 1951. Essas fotos resultaram de um trabalho conjunto para página semanal El Psicoanálisis le ayudará: as leitoras enviavam à revista seus sonhos, que por sua vez, eram analisados por dois psicanalistas. Estes profissionais escreviam as interpretações dos sonhos, os quais eram visualmente representados pelas fotomontagens de Grete. As sonhadoras revelaram-se mulheres encapsuladas, agônicas, al borde de um ataque de nervios, refletindo os padrões 
de uma sociedade machista argentina - a liberação do desejo se manifesta através dos sonhos. A interpretação final dos sonhos dessas mulheres, expressadas no trabalho de Grete, era resultante da interação de três diferentes olhares: delas próprias pela revelação nos sonhos, dos psicanalistas através da interpretação e da fotógrafa, que construía fotomontagens baseadas na descrição interpretativa ${ }^{3}$. O que podemos constatar, nessas visões apresentadas acima, é que há momentos no trabalho de campo onde não é possível separar objeto pesquisado de sujeito pesquisador, pois ambos são sujeitos.

A antropóloga Favret-Saada ${ }^{4}$ propõe que o antropólogo se deixe afetar, durante o seu trabalho de campo, para melhor apreender a subjetividade da cultura pesquisada. Afetos que não tem o sentido de emoções, mas simplesmente daquilo que afeta, atinge, modifica, aumentando ou diminuindo a potência do indivíduo. Ou seja, situar-se ao nível do afeto não representado, pois, segundo a autora, a etnologia francesa e a psicanálise estão presas aos aspectos intelectuais da experiência humana, na medida em que atribuem ao afeto um único destino possível, que consiste em passar para o registro da representação. Desse modo, nos encontros com os atores sociais, Favret-Saada enfatiza o deixar-se afetar, sem procurar pesquisar, nem mesmo compreender e reter. E, logo após o encontro, redigir um tipo de crônica dos eventos vivenciados, que servirão, mais tarde, a uma operação de conhecimento em busca da "pureza" do objeto pesquisado. Enfim, a proposta dessa autora é colocar no centro das análises a comunicação não verbal - não intencional e involuntária - e o livre jogo de afetos desprovidos de representação.

\section{Imagens do trabalho de coletores e catadoras de lixo}

Nesta parte descrevemos estudos realizados com coletores de lixo da Comlurb e com catadoras da Vila Dique na cidade de Porto Alegre no Rio Grande do Sul, que utilizam a imagem como instrumento metodológico na pesquisa qualitativa.

Processo de trabalho e coletores de lixo

A atuação da Comlurb se dá de forma descentralizada, possuindo 26 Gerências Regionais de Operações, cuja área de atuação coincide com as regionais administrativas. A regional descrita no presente artigo foi a Gerência de Limpeza Leste (GLL-3) situada no bairro do Rio Comprido.

A pesquisa utilizou como instrumentos me- todológicos a entrevista direcionada aos trabalhadores sobre os acidentes relacionados ao trabalho (ACT) e as imagens do processo de trabalho registradas em $\mathrm{DVD}^{5}$.

Velloso $^{6}$ filmou o processo de trabalho da coleta do lixo em favelas, unidades residenciais (casas e edifícios), indústrias (gráficas e farmacêuticas) e presídio - com um grupo composto por quatro coletores, em quatro dias consecutivos. $\mathrm{Na}$ filmagem preliminar os coletores apresentavamse com uniforme em estado precário, sem botas e, às vezes, sem luvas. Ao contrário, na ocasião das filmagens definitivas, esses trabalhadores trajavam uniforme completo (camisa e calça comprida, botas, boné e luvas), apesar de terem sido observados alguns trabalhadores sem as luvas.

Segue abaixo a descrição do filme, ressaltando a importância do uso da imagem na produção do conhecimento - no caso, em relação à saúde do trabalhador - que vai além da fala desses atores sociais, permitindo identificar determinados comportamentos do cotidiano, que muitas vezes podem se contrapor à fala do trabalhador.

Nas favelas visitadas, o veículo coletor sobe até um determinado ponto do morro, onde existe de forma muito precária um reservatório para recolher o lixo proveniente das casas. Tal reservatório consiste em uma construção de cimento baixa e mal acabada, onde os trabalhadores entram abaixados. Os resíduos são depositados em sacos plásticos ou simplesmente jogados sem embalagens - restos de alimentos, dejetos humanos compõem sua maior parte e já se encontram em adiantado estado de decomposição, sendo necessário o uso de uma peneira para coletar esses resíduos e em seguida varrer a poeira residual. Nestas circunstâncias, o coletor fica exposto aos riscos biológicos (às doenças através do contato com microorganismos infectantes); aos riscos químicos (poeira excessiva); riscos mecânicos (cortes e ferimentos); riscos ergonômicos (posturas inadequadas) e riscos físicos (altas temperaturas).

Nas unidades residenciais, principalmente nas casas, o lixo ainda é acondicionando em recipientes de diversos tipos e tamanhos, às vezes sem embalagens, obrigando os coletores a realizarem a operação de varredura dos resíduos que caem e permanecem no solo. O ruído produzido na compactação do lixo somado ao barulho do trânsito ocasiona perdas auditivas ao trabalhador. A impaciência dos motoristas e o intenso fluxo de veículos nas ruas causam estresses e riscos de atropelamentos. 
As operações de coleta nas indústrias, no comércio e no presídio envolvem atividades que demandam intenso esforço físico. Estas atividades consistem no levantamento e no transporte de latões com capacidade de 50, 100, 200 litros e caçambas de 1050 litros. Os coletores ficam expostos ao ruído, à poeira, às substâncias químicas tóxicas, aos objetos perfurantes e cortantes.

O compactador de lixo localizado na parte traseira do veículo coletor, que é acionado pelo próprio trabalhador durante a coleta de lixo, pode ocasionar prensagem dos membros superiores de outro trabalhador, enquanto esse desempenha suas atividades. Pode-se observar que, como o veículo coletor é alto, existe o risco de esbarrar nos fios de eletricidade que se encontram em seu trajeto, especialmente nas ladeiras.

Cabe ressaltar que os riscos mencionados não agem sobre o trabalhador de forma isolada. Assim, o corpo do trabalhador interage com os diversos riscos existentes, podendo adoecer e sofrer acidentes.

O processo de trabalho da coleta de lixo domiciliar não é uniforme, ou seja, ele não é constituído de uma única operação, e sim de vários tipos de operação. Conforme foi observado, estas operações variam de acordo com a topografia do local, onde o lixo é acondicionado e recolhido pelos coletores.

O trabalhador, apesar de realizar tarefas que demandam esforço físico na presença de ruídos e em ritmo acelerado, não possui pausas oficializadas para descanso.

As imagens do filme confirmam as falas dos trabalhadores entrevistados referentes à necessidade de transformações no processo de trabalho da coleta do lixo na cidade do Rio de Janeiro, que pode ser observado nos seguintes depoimentos ${ }^{7}$ :

... A melhor coisa que eles poderiam fazer é dar material que a gente precisa para trabalhar - roupa, sapato e capa. Além desses, a gente não pode usar EPI por causa do esforço que a gente faz...

...Não pegar esses latões grandes de 200 litros e que não socassem bastante o lixo, para não ficar tão pesado, ainda mais quando chove, ele enche de água e fica mais pesado ainda...

...Primeiros socorros, mais conhecimento para o gari, o cara só sabe que vai pegar o lixo. Tem gente que trabalha com o lixo contaminado...

Durante o filme 6 podemos observar que eles não estavam habituados ao uso dos equipamentos de proteção individual (luvas e botas), ou ainda, que esses não estavam adaptados ao trabalhador, ocasionando perda do tato e dificuldades em caminhar ou correr. Fato que poderia levá-los a não utilizar tais equipamentos de proteção. Nas entrevistas ${ }^{5}$, alguns comentaram o desconforto que sentiam ao usarem luvas - dermatite de contato e dificuldade em pegar os objetos. Ou seja, na filmagem preliminar, os coletores de lixo se apresentaram desprovidos de EPI (luvas e botas). Já nas filmagens definitivas, quando foram informados sobre a pesquisa, estavam de uniforme, botas e luvas. Isso sugere que os coletores tinham se arrumado para serem filmados, mostrando aquilo que gostariam de aparentar e tal "disfarce", também propiciou interpretações. No caso, os trabalhadores buscavam a "aparência desejada" à empresa, mas inadequada ao desempenho de suas atividades, uma vez que, as imagens do filme tornam visível o esforço despendido na realização de suas tarefas quando usavam tais equipamentos.

O DVD e a pesquisa escrita com suas recomendações foram encaminhados pelos pesquisadores à gerência da Comlurb. Atualmente podemos observar algumas mudanças no processo de trabalho dos coletores nos bairros da zona sul (frequentado por segmento social mais abastado e turistas) do município do Rio de Janeiro o latão de 200 litros foi substituído pelo carrinho de coleta com rodas e adaptado para suspensão no veículo coletor, evitando o risco do esforço excessivo ao trabalhador. Os uniformes e as botas apresentam sinalização de segurança para chamar atenção dos motoristas, protegendo os coletores contra os atropelamentos.

\section{A catadora e o objeto adquirido}

A fotografia surge no início do século XX, sendo percebida como um retrato da realidade. Paralelamente, no mesmo período, aparece nos Estados Unidos, a chamada fotografia de documentação, que são técnicas de registrar situações, buscando evidências da realidade social. Muitos fotógrafos se dedicam a essa tarefa, no entanto, Lewis Hine se tornou um dos mais conhecidos pelos seus registros sobre as condições de trabalho dos imigrantes e do trabalho infantil nos EUA. Hoje sabemos que a fotografia não é apenas um retrato da realidade, é também uma construção permeada pelo olhar/subjetividade do fotógrafo, podendo ser considerada uma obra de arte. Em 1939, os antropólogos Margareth Mead e Gregory Bateson retornam de Bali e Nova Guiné com um vasto material fotográfico e filmográfico, trabalho que se tornou referência importante para a antropologia visual contemporânea. Além das imagens, também recolheram depoimentos para registrar a cultura do grupo estudado. Não 
foram os primeiros a levar câmeras para campo, mas talvez tenham sido os primeiros a usar os recursos visuais como principal ferramenta no trabalho de levantamento de dados etnográficos. Mead e Bateson nos fizeram perceber que materiais visuais, como fotografias, antes de serem cópias da realidade, são como os textos, constituem afirmações e interpretações sobre o real ${ }^{8}$.

Baseado nesta proposta, na década de 1990 , Achutti $^{8}$, jornalista e antropólogo, no seu estudo "Antropologia visual sobre cotidiano, lixo e trabalho", utilizou na pesquisa com as catadoras de lixo de Porto Alegre, além da observação participante registrada em diário de campo, a fotografia. A proposta do autor consistia em fotografálas não somente nas suas atividades de trabalho, mas também cenas de suas vidas cotidianas. As fotos eram retornadas às atoras sociais no dia seguinte, sendo flagrante a alegria ao se identificarem nas imagens fotográficas. Achutti fotografou também as catadoras admirando as fotos do dia anterior. De acordo com ele, a imagem é capaz de dizer mais do que a fala ou o texto escrito. $\mathrm{O}$ instrumento utilizado na sua pesquisa foi basicamente a fotoetnografia - trabalho antropológico baseado na fotografia. Inspirado na obra de Geertz, Achutti ${ }^{8}$ escreve que se o trabalho do antropólogo está fundamentado na interpretação de culturas alheias, nada melhor, para realizar este trabalho, do que lançar mão de estratégias as mais diversificadas e criativas possíveis. Quanto mais ricas forem tais estratégias de abordagem, mais interessante será a forma de apresentar suas interpretações.

Em seu livro, o autor oferece ao leitor duas portas de entrada, ou seja, ao iniciarmos o livro de trás para frente mergulhamos na profundidade das imagens e, de frente para trás poderemos empreender a leitura do texto. $\mathrm{O}$ autor desenvolve uma forma narrativa - fotoetnografia - de descrever a vivência cultural de determinado grupo social. Ele opta pela narrativa visual registrada por meio de fotos no seu diário de campo e pelos depoimentos das catadoras de lixo durante o trabalho, ou seja, sua intenção é inverter, fazer com que a imagem fotográfica registrada no seu diário de campo ganhe destaque em relação ao texto.

O estudo é desenvolvido numa comunidade de catadores, sendo a maioria de origem rural da região das colônias alemãs da cidade de Porto Alegre/Rio Grande do Sul. A comunidade denominada "Vila Dique" está situada junto ao entreposto de abastecimento de frutas e verduras central da cidade (CEASA), o que propicia que os restos de alimentos ali comercializados sejam utilizados como fonte de alimentação desta população. As mulheres trabalhadoras organizaram uma cooperativa de catadoras de lixo e em um galpão selecionam o lixo, que já vem de uma coleta seletiva realizada pelo Departamento de Limpeza Urbana da Prefeitura Municipal de Porto Alegre (DMLU). Apesar da precariedade das condições de trabalho, a cooperativa das catadoras de lixo pode ser considerada como um caso bem sucedido de mobilização e organização, além de exemplar no que se refere à transformação do lixo. A partir de uma perspectiva ecológica encontram-se as estratégias de reciclagem, que propiciam um novo enfoque para o lixo - ele não representa mais o fim de uma cadeia de consumo e sim o fim do desperdício, as modernas soluções para o meio ambiente e uma nova fonte na produção de matéria-prima.

Neste contexto, o autor busca investigar os elementos com os quais esta população constrói os traços de sua identidade. Ou seja, que tipo de apropriação os outros fazem do lixo produzido e rejeitado por nós. Como se dá o processo de trabalho de separação do lixo, a organização do espaço de suas casas na construção de estratégias de reprodução social e, enfim, quem são estas mulheres.

Entre imagens e falas vamos enfocar as fotografias de Achutti, que começa seu livro mostrando a Vila Dique com suas casas humildes, separadas do lixo por uma frágil cerca de arame. As conquistas das catadoras obtidas por meio da Associação estão retratadas em suas fotos: um posto de saúde comunitário e homens construindo um espaço para o trabalho da separação dos resíduos. Podemos observar na porta da construção uma tabuleta com as seguintes nomeações: "Associação de Catadoras de Materiais Recicláveis, Apoio da DMLU e do Unibanco/Administração popular”. Neste galpão podemos ver várias mulheres entre muitos e diversos tipos de resíduos. $\mathrm{Na}$ entrada, três latões vazios próximos ao veículo coletor de lixo, que acabou de despejar seu conteúdo para serem separados pelas trabalhadoras.

Entre grande quantidade de lixo, as mulheres separam de acordo com o tipo de resíduo - plásticos, latas, jornais - que são encaminhados para uma prensa, onde são prensados e amarrados para serem transportados às usinas de reciclagem.

Durante o trabalho, as mulheres encontram "objetos de valor", que são admirados por elas. A série de fotografias de uma jovem mulher que encontra uma boneca sem braços, mas quase 
perfeita - vira a boneca de bruços, percebendo a existência de um lugar para pilhas; consegue duas pilhas no lixo e com muita expectativa leva a boneca ao ouvido em busca de escutar seu choro.

Suas casas são simples e bem arrumadas, considerando suas vidas humildes. Vemos armários com mantimentos, paredes em tijolos com tecidos improvisados como cortinas, bichinhos de pelúcia e quadros, que com certeza foram desprezados e que agora adquirem novo valor, dono e lugar. O objeto adquirido é contemplado, valorizado e utilizado nas casas das catadoras. Entre flores, imagens de santos, ursos de pelúcia e cortina de filó observamos como essas mulheres organizam suas casas e seu trabalho, procurando alcançar melhores condições de vida.

$\mathrm{O}$ autor propõe um hiato de silêncio para que se venha à tona a percepção destes rostos, olhares, formas, texturas, planos, cores e volumes que constituem também um mundo, pois são características visíveis de determinado segmento social. O desejo de Achutti é trabalhar com o acúmulo das experiências visuais de cada observador. Ou seja, trabalhar com sua alma e sensibilidade em ação, propiciando um ângulo a mais na delicada tarefa de traduzir pessoas, valores, comportamentos, coisas, arranjos sociais, crenças, ódios, dores e esperanças.

\section{Considerações finais}

Considerando a imagem, assim como o texto escrito, interpretações da realidade, constatamos que a imagem pode tanto ser um instrumento quanto um complemento na pesquisa qualitativa em saúde. A construção da imagem pode tanto servir à arte quanto ser um instrumento para a pesquisa científica. Assim como a antropologia - que serve eminentemente aos interesses da ciência -, também ela se aproxima da literatura, na medida em que constrói a realidade a partir de um acontecimento já ocorrido no passado, descrito e narrado pelo ator social (em primeira mão). É nesse sentido que o pesquisador escreve o mesmo fato interpretando-o (segunda mão), ou seja, ele interpreta o que o ator social interpretou acerca do ocorrido descrito ${ }^{2}$.

Favret-Saada ${ }^{4}$ é mais ousada no campo da antropologia, na medida em que propõe que o próprio pesquisador participe do acontecimento pesquisado, deixando-se afetar pela subjetividade do objeto. Ela propõe que haja uma interação entre o pesquisador e o objeto pesquisado, no momento em que o acontecimento se dá. Se- gundo Favret-Saada, a metodologia da observação participante na Antropologia é comumente vivenciada mais sob a forma da observação do que da participação. O que ela propõe é que o pesquisador não deve só observar, deve também interagir/participar deixando-se afetar pelo acontecimento. Mas, ao retornar do campo, ele deve procurar se distanciar do objeto, apreendendo os significados da experiência vivenciada para melhor entender a subjetividade do grupo social estudado.

A interpretação de determinada cultura envolve a interação de diferentes olhares. O trabalho do antropólogo também pode se aproximar do fazer do fotógrafo. Neste sentido, Grete Stern ${ }^{3}$ apresenta sua obra de fotomontagens baseada na interação de três diferentes olhares - das mulheres que escreviam narrando seus sonhos; dos psicanalistas através da interpretação e; da própria Grete na elaboração das fotomontagens.

A imagem como recurso metodológico apresentou resultados inovadores nas duas pesquisas empíricas, propiciando interpretações criativas e possibilidades de ações de intervenção.

Nos estudos descritos, os pesquisadores foram muito além da observação, interagindo com os atores sociais. Achutti participou da rotina do trabalho e da vida cotidiana das catadoras da Vila Dique, deixando-se afetar pela subjetividade dessas mulheres na busca e na conquista pela melhoria da sua qualidade de vida. A sequência de imagens da boneca encontrada no lixo mostra a emoção da catadora e também do fotógrafo, que vivenciou a expectativa do achado. Velloso $^{6}$ filmou o processo de trabalho da coleta do lixo no veículo coletor junto aos coletores. Assim, pôde interagir com os trabalhadores, vivenciando suas dificuldades - processo de trabalho inadequado ao trabalhador; impaciência dos motoristas com os coletores durante a coleta do lixo e a desvalorização da profissão de "lixeiro" no sentido de trabalhar com o resto desprezado pela sociedade.

Ao tomarmos contato com a pesquisa de Achutti observamos o valor da imagem sobreposta às falas dos atores sociais. A imagem deixa arestas para novas investigações, que não podem ser apreendidas por meio do texto escrito, estimulando o potencial de criatividade do pesquisador. Nas falas das catadoras percebemos suas expectativas com relação ao seu trabalho, ou seja, a necessidade de sobreviver transformando o resto desprezado pela sociedade - o lixo, aquilo que não apresenta mais serventia. No entanto, as imagens fotografadas por Achutti mos- 
tram uma nova perspectiva na vida dessas mulheres - sonhos, expectativas na busca de objetos e muita criatividade no aproveitamento do lixo como matéria-prima para sua sobrevivência que pode ser visualizada em sorrisos, tristezas, decepções e também esperanças na construção de uma nova condição de trabalho e qualidade de vida.

Nesse sentido, o suporte escrito e o imagético partem de uma observação, ambos são registros de representações e de interpretações. Entretanto, o suporte da imagem não funciona da mesma forma que o suporte da escrita - cada um deles constrói sua obra de forma cognitiva, afetiva e singular. A imagem tem o potencial de estimular a percepção do observador, que capta sensações transmitidas por meio de expressões faciais, tais como o olhar, o sorriso, o espanto difíceis de serem transmitidas pelas palavras ou pelo texto escrito.

Velloso et al. ${ }^{5}$ avaliaram de forma precisa, com base no registro das imagens em DVD, o processo de trabalho dos coletores de lixo, verificando que este processo não era uniforme, mas, sim, composto por diferentes operações. Tais operações variavam de acordo com a topografia do local de acondicionamento e coleta do lixo - favelas, residências, comércio, indústrias e presídio. Assim, foi possível visualizar e descrever em detalhes as diversas operações com seus respectivos riscos ao trabalhador, possibilitando as ações de intervenção.

\section{Referências}

1. Martins JS. Sociologia da fotografia e da imagem. São Paulo: Contexto; 2008.

2. Geertz C. A interpretação das culturas. Rio de Janeiro: Zahar; 1978.

3. Stern G. Os sonhos de Grete Stern. São Paulo: Museu Lasar Segall; 2009.

4. Favret-Saada J. Ser afetado. Cad. Campo 2005; 13:155161.

5. Velloso MP, Santos EM, Anjos LA. Processo de trabalho e acidentes de trabalho em coletores de lixo domiciliar na cidade do Rio de Janeiro, Brasil. Cad Saude Publica 1997; 13(4):693-700.

6. Velloso MP. Processo de trabalho da coleta do lixo domiciliar. [DVD]. Rio de Janeiro: Tec Cine Rio Ltda; 1995.
$\mathrm{Na}$ ausência desse registro, o estudo ficaria restrito à observação participante do pesquisador que só é vista no momento do acontecimento, enquanto que a imagem registrada pode ser vista/analisada quantas vezes forem necessárias. Além disso, a imagem registrada pode servir como um importante material educativo, tornando possível aos empregadores identificar os riscos ocasionados pelo processo de trabalho da coleta do lixo aos coletores.

\section{Colaboradores}

MP Velloso foi responsável pela concepção; delineamento; redação e aprovação da versão final do artigo. MBL Guimarães contribuiu na redação e revisão do artigo.

\section{Agradecimentos}

À CAPES - pelo apoio concedido para minha participação no V Congresso Ibero-Americano de Pesquisa Qualitativa em Saúde em Lisboa/Portugal, apresentando o estudo.
7. Velloso MP, Valadares JC, Santos EM. A coleta de lixo domiciliar na cidade do Rio de Janeiro: um estudo de caso baseado na percepção do trabalhador. Cien Saude Colet 1998; 3(2):143-150.

8. Achutti LE. Fotoetnografia: um estudo de antropologia visual sobre cotidiano, lixo e trabalho. Porto Alegre: Tomo Editorial Palmarinca; 1997.

Artigo apresentado em 16/05/2011

Aprovado em 13/08/2011

Versão final apresentada em 28/11/2011 